\title{
The eClinical Care Pathway Framework: a novel structure for creation of online complex clinical care pathways and its application in the management of sexually transmitted infections
}

\author{
Jo Gibbs ${ }^{1,2^{*}}$ (D) Lorna J. Sutcliffe ${ }^{1}$, Voula Gkatzidou ${ }^{3}$, Kate Hone ${ }^{3}$, Richard E. Ashcroft ${ }^{4}$, Emma M. Harding-Esch" ${ }^{5}$, \\ Catherine M. Lowndes ${ }^{5}$, S. Tariq Sadiq ${ }^{6}$, Pam Sonnenberg ${ }^{2}$ and Claudia S. Estcourt ${ }^{1}$
}

\begin{abstract}
Background: Despite considerable international eHealth impetus, there is no guidance on the development of online clinical care pathways. Advances in diagnostics now enable self-testing with home diagnosis, to which comprehensive online clinical care could be linked, facilitating completely self-directed, remote care. We describe a new framework for developing complex online clinical care pathways and its application to clinical management of people with genital chlamydia infection, the commonest sexually transmitted infection (STI) in England.

Methods: Using the existing evidence-base, guidelines and examples from contemporary clinical practice, we developed the eClinical Care Pathway Framework, a nine-step iterative process. Step 1: define the aims of the online pathway; Step 2: define the functional units; Step 3: draft the clinical consultation; Step 4: expert review; Step 5: cognitive testing; Step 6: user-centred interface testing; Step 7: specification development; Step 8: software testing, usability testing and further comprehension testing; Step 9: piloting. We then applied the Framework to create a chlamydia online clinical care pathway (Online Chlamydia Pathway).

Results: Use of the Framework elucidated content and structure of the care pathway and identified the need for significant changes in sequences of care (Traditional: history, diagnosis, information versus Online: diagnosis, information, history) and prescribing safety assessment. The Framework met the needs of complex STI management and enabled development of a multi-faceted, fully-automated consultation.
\end{abstract}

Conclusion: The Framework provides a comprehensive structure on which complex online care pathways such as those needed for STI management, which involve clinical services, public health surveillance functions and third party (sexual partner) management, can be developed to meet national clinical and public health standards. The Online Chlamydia Pathway's standardised method of collecting data on demographics and sexual behaviour, with potential for interoperability with surveillance systems, could be a powerful tool for public health and clinical management.

Keywords: Online clinical care pathway, Framework, eHealth, Sexual health, Sexually transmitted infections, Chlamydia trachomatis

\footnotetext{
*Correspondence: jo.gibbs@ucl.ac.uk

'Blizard Institute, Barts and The London School of Medicine \& Dentistry,

Queen Mary University of London, London, UK

${ }^{2}$ Research Department of Infection and Population Health, University College

London, Mortimer Market Centre, off Capper Street, London, UK

Full list of author information is available at the end of the article
} 


\section{Background}

In common with many other countries, UK has a prominent $e$ Health agenda which prioritises self-led and remote care [1-3]. Most eHealth to date has focused on monitoring and management of long-term health conditions, such as asthma, diabetes and hypertension, offered as an adjunct to traditional care [4-6]. Typically patients first receive their medical diagnosis from a healthcare professional in a face-to-face consultation, with opportunities to discuss their condition and its management, before digital technologies such as apps for adherence, health promotion and symptom diaries [4-20] are offered.

Analogous to home pregnancy testing, new infectious disease diagnostic technology means that people will be able to self-test for various infections at home and will be able to self-diagnose with a new medical condition remote from medical services. This could have considerable benefits, particularly for people with stigmatizing infections such as sexually transmitted infections (STIs) and HIV, as people report barriers to accessing services and highly value accessibility and convenience of medical care [21-25]. In England, the major burden of STIs occurs in young people [26]. This group has high smartphone and internet usage, with $88 \%$ of $16-24$ year olds owning a smartphone, and being rapid adopters of new technology [27].

The development of home STI diagnostics creates potential for developing a completely remote online clinical care pathway, from diagnosis through to management. However, UK national standards for STI management contain multiple facets of care [28] which are far more complex than simply prescribing antibiotics. These include sexual partner management, health promotion, sign-posting to other related services and collection of data for routine public health surveillance purposes, whilst maintaining data security and patient confidentiality [29]. All these elements would need to be incorporated within an online care pathway for National Health Service use.

Currently there is no guidance in England on the development and content of online clinical care pathways ('structured multidisciplinary plans of anticipated care' [30]), and, in particular, no guidance specific to sexual health.

Here we describe a new framework for development of complex online clinical care pathways (see Methods) and demonstrate its utility for development of a system for management of genital Chlamydia trachomatis infection (see Results), the commonest STI in England [26], using an online automated clinical consultation followed by remote prescribing and sexual partner management.

\section{Methods}

\section{Development of the framework}

Using the existing evidence base, guidelines and examples from contemporary clinical practice, we developed the $e$ Clinical Care Pathway Framework. For the Online
Chlamydia Pathway, intended to take users, who have tested using a variety of routes, from accessing test result, and therefore diagnosis, through automated medical assessment and on to treatment, we undertook a comprehensive literature review of published and grey literature. We were unable to identify any validated tools or methods to guide the development of a remote online automated clinical care pathway. However, there was information available that could be used to indirectly inform the development of such a pathway. We synthesised our findings to develop the Framework creating a nine-step iterative process (Fig. 1).

This included evidence on Step 1 (aims) [31, 32], Step 2 (pathway sequence) [33], Step 3 (online consultation) [34], Step 4 (expert review) [34-36], Step 5 (cognitive testing) [37-41], Step 6 (interface testing) [39, 42, 43], Step 8 (software and usability testing) [32, 33, 35, 39, 44, 45] and Step 9 (pilot) [31, 35, 41].

Step 1 is to define the aims of the online clinical care pathway. Step 2 requires definition of the functional units by breaking down the clinical care pathway into sections (for example history, examination and investigations (screening or diagnostic tests) based around the traditional aspects of clinical care it contains. It is important to consider whether the sequence needs to be different to traditional care. For example, in a traditional clinical care pathway sequence where a patient comes into clinic, the initial functional unit is the presenting complaint and history of presenting complaint. In an online clinical care pathway this may not be appropriate, particularly if the pathway is linked to, for example, remote self-testing and diagnosis.

Step 3 involves drafting the automated online clinical consultation which is likely to be a key component of most clinical care pathways. This is the "automated medical assessment" which includes history-taking, decisionmaking and easily extractable and transmissible surveillance data. Composed of clinical and behavioural questions, it is designed to determine whether it is safe and appropriate to proceed with remote management of the condition. Relevant published literature, proformas and protocols in contemporary use, standards and existing services provide a robust evidence-base for the online consultation.

Step 4 involves review of the draft consultation by clinical experts with respect to the content, phrasing and flow of questions and text. Any issues where it is not possible to reach consensus as part of this process can be focussed on as part of Step 5 and Step 6. Immediately following this it is important to ensure that users comprehend and interpret the text and questions correctly. This can be done by cognitively testing [46] (Step 5) the text and questions with a sample of your target population. 


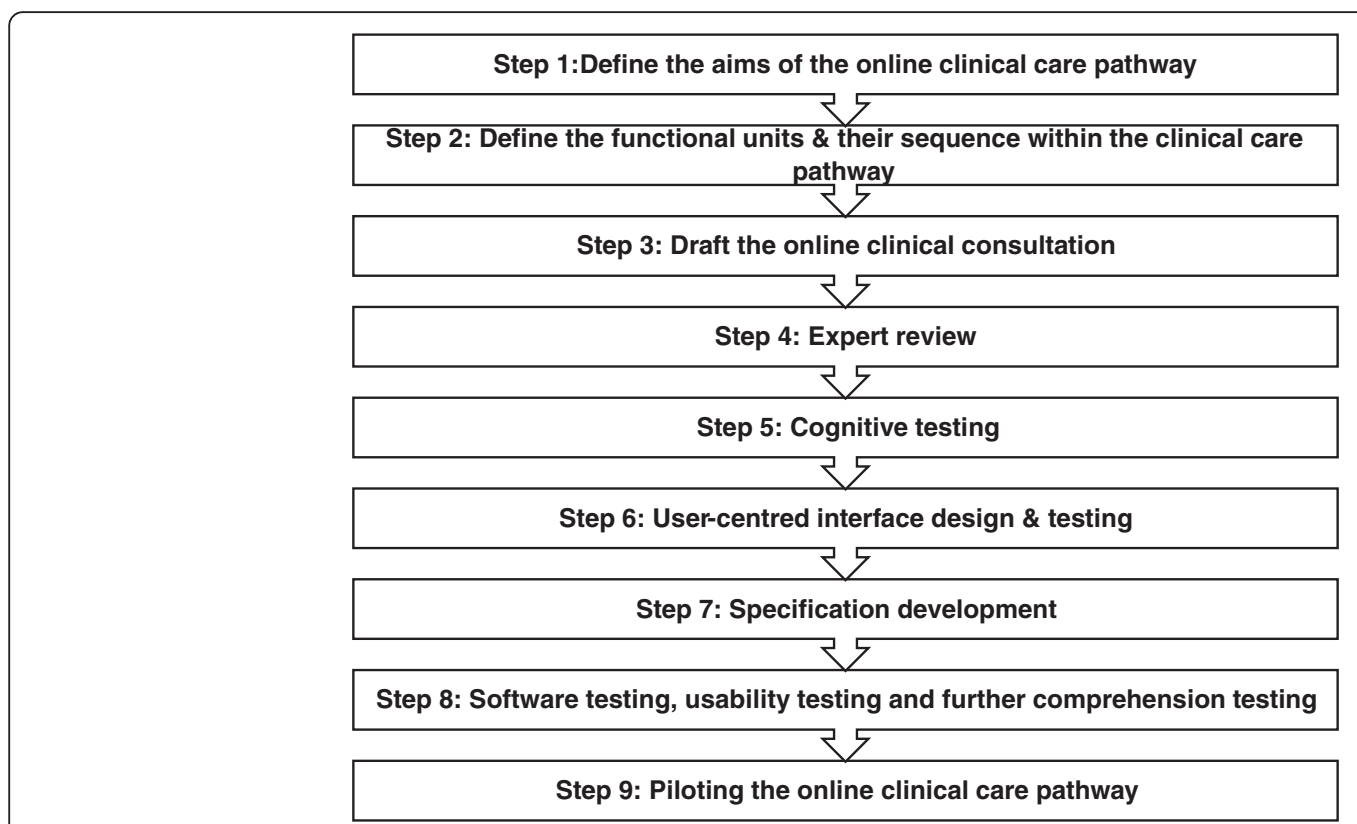

Fig. 1 eClinical Care Pathway Framework

Step 6 involves user-centred interface design and testing. For user-centred interface design the question set is translated into a format that works on the chosen screen resolutions with the appropriate response options. It is important to use relevant user interface design guidelines as a basis for this [42]. The purpose of testing is to focus on the users' views of the interface, how the information is presented and the order of the interactive steps in the user interface.

Step 7 requires conversion of the online clinical consultation into a database specification in order for software engineers to design the system according to one's needs. This process is described in more detail in the results section below and includes translation of the database specification in to wireframes to specify the user interface to achieve the optimal design output. Once the software engineers have produced an application (app), further expert usability review, software testing, usability testing and comprehension testing can be conducted by a clinical researcher and Human Computer Interface expert (Step 8). Finally, Step 9 involves piloting of the online clinical care pathway with the target population, with further refinement occurring on the basis of findings and evaluation of this.

\section{Application of the framework to chlamydia}

Once the Framework was developed, we then applied it to our exemplar condition, genital chlamydia to produce the Online Chlamydia Pathway. Chlamydia is an ideal candidate infection as it is common, and there is a standard first line antibiotic therapy, Azithromycin $1 \mathrm{~g}$ orally [47]. Azithromycin has good tolerability, a low side-effect profile, and allergy and drug interactions are infrequent among the target population [48-53].

This phase involved:

1. Sourcing of national and international clinical standards for sexual history taking, chlamydia management, health promotion, sexual health service provision, consent, good medical practice, and prescribing

2. Collation of protocols ('a comprehensive set of rigid criteria outlining the management steps for a single clinical condition or aspects of organisation' [30]) and proformas in use in contemporary sexual health settings

3. Literature search for evidence on provision of STI results and the individual components of the online clinical consultation

4. Collation of sexual health questionnaires and computer assisted structured interviews

\section{Results and discussion}

\section{Step 1: Aim}

The aim of the Online Chlamydia Pathway was to enable people with genital chlamydia to receive their test result online, obtain information about the infection, complete a clinical consultation, and for those for whom it was appropriate to do so, progress to receive a remote prescription of antibiotic treatment in a safe, efficient manner. It also needed to ensure that patients for whom it was not appropriate to be managed in this way were identified and transferred to traditional services in a timely and efficient manner. 
Further aims of the Online Chlamydia Pathway included partner notification, provision of epidemiological treatment where acceptable and appropriate for sexual partners, a two-week health adviser followup phone-call for all patients who accessed the online clinical consultation, and collection of data for national surveillance system purposes.

\section{Step 2: pathway sequence}

Use of the Framework clarified the basic sequence of functional units of care (Fig. 2), which is fundamentally different to traditional care pathways which start with the medical history, followed by examination, investigations, results and management. Our pathway had to accommodate patients entering from different types of chlamydia screening providers, each with different processes for, and content of, medical information gathering and capture at the time of testing, whilst keeping collection of patient identifiable data to a minimum. This meant that there was no patient history available at the point of diagnosis and therefore this had to be taken once the patient was already aware of the results of the investigations.

It is also possible that people may have developed new symptoms in the time between testing and diagnosis, or that they may be more candid in the face of a positive test result, and it was therefore important to establish a history specific to whether it was safe and appropriate to prescribe Azithromycin without face-to-face clinical review. This was a radical departure from traditional pathways and had major implications in terms of the information that needed to be provided and the content, phrasing, logic and order of the questions asked in the clinical consultation.

Based on the online pathway sequence, the individual functional units of the pathway were established (Fig. 3a and $b$ ). As well as the points made above, the rationale behind the order chosen included reducing the length of the interaction for those whom it was not safe to treat. In this way such patients could transfer to alternative (face-to-face) care as quickly as possible, rather than only finding this out at the end of the consultation.

\section{Step 3: online consultation}

The automated online clinical consultation consisted of functional units one to nine, as shown in Fig. 3b. For each of these units, the objective of the unit and evidence bases for the unit were analysed, with a decision then being made as to the optimal way of developing and implementing that unit. The first functional unit was a results service which required examination of the evidence base [54-67] and current practice to conclude the best way for patients to access their results. Information was collected within the online clinical consultation on basic personal and demographic details (required for both clinical needs and surveillance purposes), taking relevant medical/drug history, symptom assessment, sexual history, risk assessment, and partner notification with epidemiological treatment [38, 43, 48, 51-53, 68-108].

Those patients for whom it was assessed to be safe and appropriate were able to choose a local pharmacy from where they could collect their treatment. A clinical helpline was available to support patients' medical and psychosocial needs throughout this pathway. All patients who consented [109] were followed up with a phone call from a research health adviser at two weeks. A separate portal was developed to support the research health adviser; this included details and status of all eligible patients, details of information entered onto the system by the results administrator and patient, a screen for documenting conversations via the clinical helpline, treatment outcomes and a structured two week phone follow-up.

\section{Step 4: expert review}

The expert review panel consisted of consultant genitourinary medicine and public health physicians, academics in sexual health, public health, human computer interaction, bioethics and a research health adviser.

Traditional clinical care pathway:

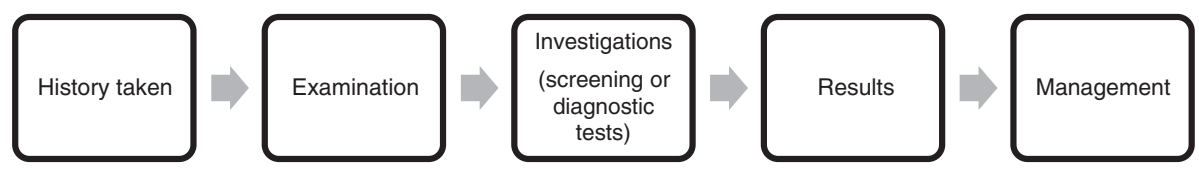

Online clinical care pathway:

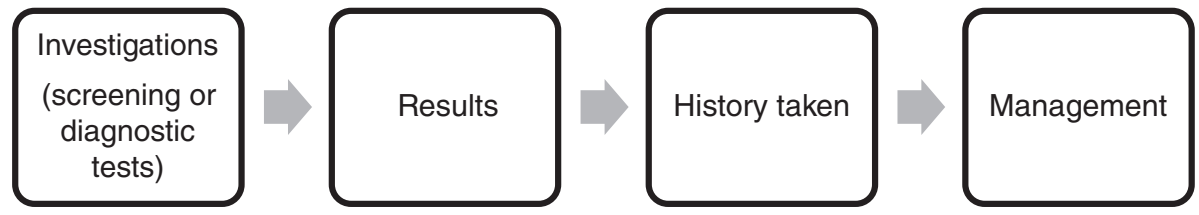

Fig. 2 Contrast between the basic sequence of functional units of care in traditional clinical care pathways and online clinical care pathways 
a $\quad$ b

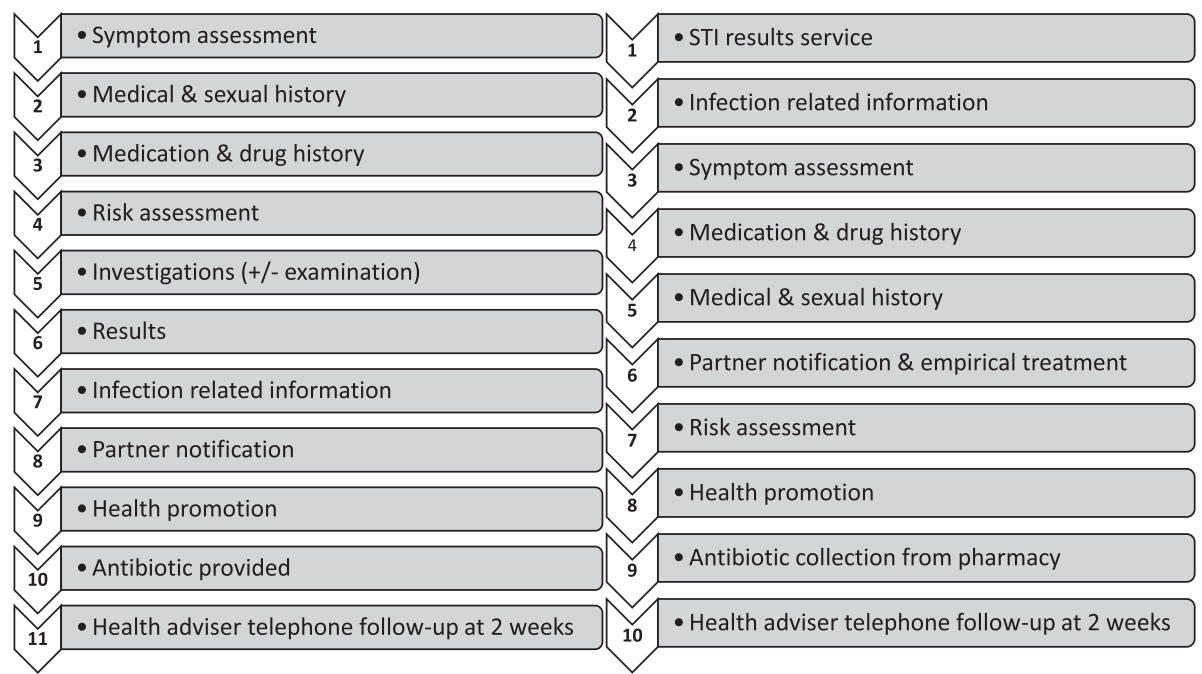

Fig. 3 a Functional units of a traditional sexual health pathway. b Functional units of the Online Chlamydia Pathway

Feedback from the panel led to amendments to the content and phrasing of the text and questions within the online clinical consultation.

\section{Step 5: cognitive testing}

Beatty and Wallis define cognitive testing as 'the administration of draft survey questions while collecting additional verbal information about the survey response, which is used to evaluate the quality of the response or to help determine whether the question is generating the information that its author intends' [110]. Cognitive testing was conducted with members of the public. One of the main findings from this was that people either did not know what azithromycin (a macrolide and first-line treatment for chlamydia [93]) was or confused it with erythromycin. This meant that they were unable to accurately interpret and answer the question relating to allergies. It was therefore necessary to develop a series of questions which allowed patients with no allergies to pass on to the next section whilst ensuring that any patients who were allergic to macrolides came off the online pathway and into clinic.

\section{Step 6: user-centred interface design and testing}

Initial focus groups were conducted by a Human Computer Interaction researcher in university and secondary schools in order to establish user requirements [42]. User interface design principles and guidelines were then used to design the interface to ensure optimal display of questions and response sets, along with facilitating the user journey and flow of interaction. Lab-based user interface testing was conducted with wire-framed prototypes.

\section{Step 7: specification development}

A specification was developed in Microsoft Excel which included text, logic, data item numbering, field names and the export data sheet. This was sent to the software engineers, along with the user interface design wireframes (which specified the look and feel of the interface and clarified the user journey) for development of a demonstration version of the pathway.

\section{Step 8: software and usability testing}

Further software, usability and cognitive testing was then conducted with the demonstration version of the pathway before the system went live. This included the Human Computer Interaction researcher conducting an expert usability review and lab-based testing with members of the public, and repeated testing of the system to ensure that it was accurate, fully functional and coded correctly.

\section{Step 9: pilot}

The Online Chlamydia Pathway has been successfully piloted in an exploratory study involving patients recruited from Sexual Health Clinics and the National Chlamydia Screening Programme in England [111].

\section{Conclusions}

Despite the increasing uptake of eHealth within the NHS, at present there is no guidance available on the development of online clinical care pathways. There are fundamental differences between the approach taken with online compared to traditional clinical care pathways. These include the sequence of the pathway, which questions are asked and how the text is phrased, ensuring that it is safe and appropriate for the patient to be managed 
online and providing an alternative rapid pathway into care for those patients for whom it is not appropriate.

We developed a new framework for complex online clinical care pathways and adapted it for use for management of genital Chlamydia trachomatis infection. The Framework is a useful structure for developing an online clinical care pathway. We have used it here to develop a complex online clinical care pathway for chlamydia which provides the services, data collection, surveillance function and standards a patient would have if attending a traditional service, within an easy and acceptable format. This Online Chlamydia Pathway is compliant with relevant standards and guidance. This is a new method of developing an automated online clinical consultation which is logical, comprehensive and aims to provide users with the ability to choose the management pathway which best suits them, and is most appropriate for them, whilst maintaining a high standard of care. The methodology used could be applied and adapted to a wide range of conditions outside Sexual Health.

We have focused here on a common treatable bacterial STI (Chlamydia trachomatis). However, the pathway could be adapted to incorporate testing and managing other STIs, and other services. Indeed, study patients received negative results via the Online Chlamydia Pathway results service for other STI tests they had in clinic. As well as potentially reducing the time to treatment for index patients, and increasing the proportion of patients treated appropriately within the community, this standardised method of collecting data on demographics and sexual behaviour, with easily extractable data and the potential for interoperability with surveillance systems, could be a powerful tool for public health and clinical care. In order to complete this type of process effectively requires effective multi-disciplinary collaboration.

\section{Abbreviations}

NHS, The United Kingdom's National Health Service; STI, Sexually Transmitted Infection

\section{Acknowledgements}

We are very grateful to Catherine Aicken, Sue Eaton and Ala Szczepura for their helpful comments when developing and applying this Framework.

\section{Funding}

UKCRC Translational Infection Research (TIR) Initiative supported by the Medical Research Council, eSTI2 Consortium (Grant Number G0901608). The funding body had no role in the design or application of the Framework, in the writing of the manuscript and in the decision to submit the manuscript for publication.

\section{Availability of data and materials}

Not applicable, because raw data were not used in this research.

\section{Authors' contributions}

The paper was conceived by JG, CSE and PS. JG wrote the first draft, with further contributions from $\mathrm{KH}, \mathrm{EMHE}, \mathrm{CML}$, STS, PS and CSE. JG conducted the initial literature review and JG, CSE, VG and LS developed the Framework. JG, LS, VG and CSE applied the framework to the Online Chlamydia Pathway. EMHE and CML provided input on the surveillance component of the pathway. $L S, V G, K H$,
REA, EMHE, CML, STS, PS and CSE participated in Step 4 (Expert Review Panel). VG and KH conducted Step 6 (user-centred interface design and testing). JG, LS, VG and KH conducted Step 8 (software and usability testing). KH, CML, STS (Principal Investigator), PS and CSE, were applicants on the eSTI2 Consortium grant, wrote the initial protocol and obtained funding. PS led the Clinical, Public Health and Economics work stream. CSE led the exploratory study of the Online Chlamydia Pathway with contributions from JG, $\sqcup S, V G, K H, R E A$, EMHE, CML,

STS, and PS. All authors read and approved the final manuscript.

\section{Competing interests}

The authors declare that they have no competing interests.

\section{Consent for publication}

Not applicable.

\section{Ethics approval and consent to participate}

Ethical approval and consent to participate was not required for this research. This complies with national guidelines [112]. Ethical approval was gained for the Online Chlamydia Pathway exploratory studies (Brighton \& Sussex (NHS) Research Ethics Committee, REC reference 13/LO/1111; IRAS project ID: 112513).

\section{Author details}

'Blizard Institute, Barts and The London School of Medicine \& Dentistry, Queen Mary University of London, London, UK. ${ }^{2}$ Research Department of Infection and Population Health, University College London, Mortimer Market Centre, off Capper Street, London, UK. ${ }^{3}$ School of Information Systems \& Computing, Brunel University London, Uxbridge, UK. ${ }^{4}$ School of Law, Queen Mary University of London, Mile End Road, London, UK. ${ }^{5} \mathrm{HIV} / \mathrm{STI}$ Department, Public Health England, London, UK. Institute of Infection and Immunity, St George's, University of London, London, UK.

Received: 11 January 2016 Accepted: 13 July 2016

Published online: 22 July 2016

\section{References}

1. England NHS. Putting Patients First: The NHS England business plan for 2013/4-2015/6. 2013. http://www.england.nhs.uk/wp-content/uploads/ 2013/04/ppf-1314-1516.pdf.

2. England NHS. NHS Commissioning Board launches library of NHS-reviewed phone apps to keep people healthy. 12-3-2013. 24-6-2013. http://www. england.nhs.uk/2013/03/12/nhs-apps/.

3. England NHS. Safer hospitals, safer wards: achieving an integrated digital care record. 2013. p. 1-7.

4. Blake H. Mobile phone technology in chronic disease management. Nurs Stand. 2008;23:43-6.

5. Blake $\mathrm{H}$. Innovation in practice: mobile phone technology in patient care. $\mathrm{Br}$ J Community Nurs. 2008;13:160. 162-160, 165.

6. de Jongh T, Gurol-Urganci I, Vodopivec-Jamsek V, Car J, Atun R. Mobile phone messaging for facilitating self-management of long-term illnesses. Cochrane Database Syst Rev. 2012;12:CD007459.

7. Baptist AP, Thompson M, Grossman KS, Mohammed L, Sy A, Sanders GM. Social media, text messaging, and email-preferences of asthma patients between 12 and 40 years old. J Asthma. 2011;48:824-30.

8. Krishna S, Boren SA, Balas EA. Healthcare via cell phones: a systematic review. Telemed J E Health. 2009;15:231-40

9. Pinnock H, Slack R, Pagliari C, Price D, Sheikh A. Understanding the potential role of mobile phone-based monitoring on asthma self-management: qualitative study. Clin Exp Allergy. 2007;37:794-802.

10. Klasnja P, Pratt W. Healthcare in the pocket: mapping the space of mobilephone health interventions. J Biomed Inform. 2012;45:184-98.

11. van der Meer V, van den Hout WB, Bakker MJ, Rabe KF, Sterk PJ, Assendelft WJ, et al. Cost-effectiveness of Internet-based self-management compared with usual care in asthma. PLoS One. 2011;6:e27108.

12. Ryan D, Price D, Musgrave SD, Malhotra S, Lee AJ, Ayansina D, et al. Clinical and cost effectiveness of mobile phone supported self monitoring of asthma: multicentre randomised controlled trial. BMJ. 2012;344:e1756. http://www.bmj. com/content/344/bmj.e1756.

13. Martinez-Perez B, de la Torre-Díez I, Lopez-Coronado M. Mobile health applications for the most prevalent conditions by the world health organization: review and analysis. J Med Internet Res. 2013;15:e120. 
14. Smith M, Dang D, Lee J. E-prescribing: clinical implications for patients with diabetes. J Diabetes Sci Technol. 2009;3:1215-8.

15. Mark DA, Fitzmaurice GJ, Haughey KA, O'Donnell ME, Harty JC. Assessment of the quality of care and financial impact of a virtual renal clinic compared with the traditional outpatient service model. Int J Clin Pract. 2011;65:1100-7.

16. Jeffery R, Iserman E, Haynes RB. Can computerized clinical decision support systems improve diabetes management? A systematic review and metaanalysis. Diabet Med. 2012

17. Ebrahiminia V, Riou C, Seroussi B, Bouaud J, Dubois S, Falcoff H, et al. Design of a decision support system for chronic diseases coupling generic therapeutic algorithms with guideline-based specific rules. Stud Health Technol Inform. 2006;124:483-8.

18. Austin BS, Gunlock TL, Krishna S, Kramer TC. Computer-aided diabetes education: a synthesis of randomized controlled trials. AMIA Annu Symp Proc 2006, 51-55.

19. Boyce N. The lancet technology: June, 2012. Maps, apps-and evidence? Lancet. 2012;379:2231.

20. Muessig KE, Pike EC, Legrand S, Hightow-Weidman LB. Mobile phone applications for the care and prevention of HIV and other sexually transmitted diseases: a review. J Med Internet Res. 2013;15:e1.

21. Kinghorn GR. Patient access to GUM clinics. Sex Transm Infect. 2001;77:1-2.

22. Foley E, Patel R, Green N, Rowen D. Access to genitourinary medicine clinics in the United Kingdom. Sex Transm Infect. 2001;77:12-4.

23. Thomas M, Dixon K, Ali AH, Patel R, Robinson AJ, Yuen HM, et al. Young persons' access to genitourinary medicine clinics in the UK: a cross-sectional survey. Sex Transm Infect. 2012;88:348-51.

24. Saunders JM, Mercer CH, Sutcliffe $\sqcup$, Hart GJ, Cassell J, Estcourt CS. Where do young men want to access STI screening? A stratified random probability sample survey of young men in Great Britain. Sex Transm Infect. 2012;88:427-32.

25. Mercer CH, Aicken CR, Estcourt CS, Keane F, Brook G, Rait G, et al. Building the bypass-implications of improved access to sexual healthcare: evidence from surveys of patients attending contrasting genitourinary medicine clinics across England in 2004/2005 and 2009. Sex Transm Infect. 2012;88:9-15.

26. Public Health England. Health Protection Weekly Report: Sexually transmitted infections and chlamydia screening in England, 2014. 2015. 3-11-2015. https:// www.gov.uk/government/uploads/system/uploads/attachment_data/file/ 437433/hpr2215_STI_NCSP_v6.pdf.

27. Ofcom. The Communication Market 2014. 2014. http://stakeholders.ofcom. org.uk/binaries/research/cmr/cmr14/2014_UK_CMR.pdf.

28. BASHH \& MEDFASH. Standards for the managment of sexually transmitted infections (STIs). 2014. http://www.medfash.org.uk/uploads/files/ p18dtqli8116261rv19i61rh9n2k4.pdf.

29. Harding-Esch E, Nardone A, Gibbs J, Sutcliffe L, Sonnenberg P, Estcourt C, et al. Can remote STI/HIV testing and eClinical care be compatible with robust public health surveillance. 2015.

30. OPEN CLINICAL knowledge management for medical care. Clinical Pathways: multidisciplinary plans of best clinical practice. 8-7-2013. 16-82013. http://www.openclinical.org/clinicalpathways.html.

31. Medical RC. Developing and evaluating complex interventions: new guidance. 2010. 1-5-2015. www.mrc.ac.uk/complexinterventionsguidance.

32. Murray E, Treweek S, Pope C, MacFarlane AF, Ballini LF, Dowrick CF, et al. Normalisation process theory: a framework for developing, evaluating and implementing complex interventions. BMC Med. 2010;8:63.

33. May C. A rational model for assessing and evaluating complex interventions in health care. BMC Health Serv Res. 2006;6:86.

34. Health and Social Care Information Centre. NHS Pathways. 2015. 6-4-2015. http://systems.hscic.gov.uk/pathways.

35. French RS, Cowan FM, Wellings K, Dowie J. The development of a multicriteria decision analysis aid to help with contraceptive choices: My Contraception Tool. J Fam Plann Reprod Health Care. 2014;40:96-101.

36. Tideman R, Pitts M, Fairley CK. Use of the Delphi sorting technique to establish a core sexual history. Int J STD AIDS. 2006;17:170-2.

37. Erens B, Phelps A, Clifton S, Mercer CH, Tanton C, Hussey D, et al. Methodology of the third British National Survey of Sexual Attitudes and Lifestyles (Natsal-3). Sex Transm Infect. 2013

38. Aicken CR, Gray M, Clifton S, Tanton C, Field N, Sonnenberg P, et al. Improving questions on sexual partnerships: lessons learned from cognitive interviews for Britain's third National Survey of Sexual Attitudes and Lifestyles ("Natsal-3"). Arch Sex Behav. 2013:42:173-85.

39. Gustafson DH, Wyatt JC. Evaluation of ehealth systems and services. BMJ. 2004;328:1150
40. Rothrock NE, Kaiser KA, Cella D. Developing a valid patient-reported outcome measure. Clinical Pharmacology \& Therapeutics. 2011;90:737-42.

41. Weston RL, Hopwood B, Harding J, Sizmur S, Ross JD. Development of a validated patient satisfaction survey for sexual health clinic attendees. Int J STD AIDS. 2010;21:584-90.

42. Gkatzidou V, Hone K, Sutcliffe L, Gibbs J, Sadiq ST, Szczepura A, et al. User interface design for mobile-based sexual health interventions for young people: design recommendations from a qualitative study on an online Chlamydia clinical care pathway. BMC Med Inform Decis Mak. 2015;15:72.

43. McCarthy O, Carswell K, Murray E, Free C, Stevenson F, Bailey JV. What young people want from a sexual health website: design and development of Sexunzipped. J Med Internet Res. 2012;14:e127.

44. Brown III W, Yen PY, Rojas M, Schnall R. Assessment of the Health IT Usability Evaluation Model (Health-ITUEM) for evaluating mobile health (mHealth) technology. J Biomed Inform. 2013;46:1080-7.

45. Cummings E, Turner P. Patients at the centre: methodological considerations for evaluating evidence from health interventions involving patients use of web-based information systems. Open Med Inform J. 2010:4:188-94.

46. Campanelli P. Testing Survey Questions: New Directions in Cognitive Interviewing. Bulletin de Methodologie Sociologique. 1997;55:5-17.

47. British Association of Sexual Health \& HIV. 2015 UK national guideline for the management of infection with Chlamydia trachomatis.2015. 16-11-2015. http://www.bashh.org/documents/2015_UK_guideline_for_the_ management_of_Chlamydia_trachomatis_final_12...pdf.

48. eMC. Azithromycin 500mg tablets SPC. 17-9-2013. 13-11-2013. http://www. medicines.org.uk/EMC/medicine/21720/SPC/Azithromycin+500mg+Tablets/.

49. Golden MR, Whittington WL, Handsfield HH, Hughes JP, Stamm WE, Hogben $M$, et al. Effect of expedited treatment of sex partners on recurrent or persistent gonorrhea or chlamydial infection. N Engl J Med. 2005;352:676-85.

50. Schillinger JA, Kissinger $P$, Calvet $H$, Whittington WL, Ransom RL, Sternberg $M R$, et al. Patient-delivered partner treatment with azithromycin to prevent repeated Chlamydia trachomatis infection among women: a randomized, controlled trial. Sex Transm Dis. 2003;30:49-56.

51. Nahata M. Drug interactions with azithromycin and the macrolides: an overview. J Antimicrob Chemother. 1996;37(Suppl C):133-42.

52. Svanstrom $H$, Pasternak $B$, Hviid A. Use of azithromycin and death from cardiovascular causes. N Engl J Med. 2013;368:1704-12.

53. British National Formularly. BNF November 2013. 13-11-2013. http://www. medicinescomplete.com/mc/bnf/current/PHP3503-azithromycin-nonproprietary.htm\#PHP3503-azithromycin-non-proprietary.

54. Ling SB, Richardson DB, Mettenbrink CJ, Westergaard BC, Sapp-Jones TD, Crane LA, et al. Evaluating a Web-based test results system at an urban STI clinic. Sex Transm Dis. 2010.

55. Brown L, Copas A, Stephenson J, Gilleran G, Ross JD. Preferred options for receiving sexual health screening results: a population and patient survey. Int J STD AIDS. 2008;19:184-7.

56. Llewellyn CD, Sakal C, Lagarde M, Pollard A, Miners AH. Testing for sexually transmitted infections among students: a discrete choice experiment of service preferences. BMJ Open. 2013:3:e003240.

57. Martin L, Knight V, Read PJ, McNulty A. Clients' preferred methods of obtaining sexually transmissable infection or HIV results from Sydney sexual health centre. Sex Health. 2013;10:91-2.

58. Labacher L, Mitchell C. Talk or text to tell? How young adults in Canada and South Africa prefer to receive STI results, counseling, and treatment updates in a wireless world. J Health Commun. 2013;18:1465-76.

59. Evans-Jones J, Steedman N, Newman M, Jones R, Milburn A, O'Mahony C. Use of Telephonetics RESULTS computer-facilitated telephone system with automatic results upload. Int J STD AIDS. 2011;22:525-6.

60. Steedman NM, Thompson C. Telephonetics RESULTS computer-facilitated telephone system: a novel method for patient results retrieval. Int J STD AIDS. 2007;18:422-3.

61. National Chlamydia Screening Program. Text messaging for test results communication within the National Chlamydia Screening Programme. 2013. 12-5-2015. Ref Type: Online Source. https:/www.gov.uk/government/uploads/ system/uploads/attachment_data/file/508763/Chlamydia_Test_Result_ Notification_Text_Messaging_NCSP Recommendations_Jan_2013.pdf.

62. Kohn R, Williams D, Klausner JD. Getting STD Test Results Over the Internet: San Francisco, 2005. 2006 National STD Prevention Conference 9-5-2006. 13-12-1921. Ref Type: Abstract. http://cdc.confex.com/cdc/std2006/techprogram/P11122.HTM. 
63. health i. Amsterdam to launch STD clinic online. 22-10-2007. 13-12-1921. Ref Type: Online Source. http://ehi.co.uk/news/EHI/3114/amsterdam-to-launchstd-clinic-online.

64. Duncan B, Hart GF, Scoular AF, Bigrigg A. Qualitative analysis of psychosocial impact of diagnosis of Chlamydia trachomatis: implications for screening. BMJ. 2001:322:195-9.

65. Lim MSC, Hocking JS, Hellard ME, Aitken CK. SMS STI: a review of the uses of mobile phone text messaging in sexual health. Int J STD AIDS. 2008;19:287-90.

66. Lim EJ, Haar JF, Morgan J. Can text messaging results reduce time to treatment of Chlamydia trachomatis? Sex Trans Infect. 2008;84:563-64

67. Fuller SS, Sutcliffe $\amalg$, Estcourt CS, Gkatzidou V, Hone K, Sonnenberg P, et al. What are young people's perceptions of using electronic self-tests for STIs linked to mobile technology for diagnosis and care $($ eSTI2)? Sex TransmInfect. 2013;89 Suppl 1:A69. Ref Type: Abstract.

68. Lim MS, Bowring AL, Gold J, Aitken CK, Hellard ME. Trends in sexual behavior, testing, and knowledge in young people; 2006-2011. Sex Transm Dis. 2012;39: 831-4.

69. Owens Jr RC, Nolin TD. Antimicrobial-associated QT interval prolongation: pointes of interest. Clin Infect Dis. 2006;43:1603-11.

70. Shamos SJ, Mettenbrink CJ, Subiadur JA, Mitchell BL, Rietmeijer CA. Evaluation of a testing-only "express" visit option to enhance efficiency in a busy STI clinic. Sex Transm Dis. 2008;35:336-40

71. Singh RH, Erbelding EJ, Zenilman JM, Ghanem KG. The role of speculum and bimanual examinations when evaluating attendees at a sexually transmitted diseases clinic. Sex Transm Infect. 2007;83:206-10.

72. BASHH Clinical Effectiveness Group. 2013 UK national guideline for consultations requiring sexual history taking. 2013

73. Department of Health, NHS. Information Governance Toolkit. 2013.

74. Department of Health, NHS. NHS Information Governance: Information Risk Management Guidance: Short Message Service (SMS) \& Texting. 2010. 12-2-2013. http://systems.hscic.gov.uk/infogov/links/sms2010.pdf.

75. Gammell K. Mobile phone insurance: don't lose money if you lose your smartphone. 2012.28-5-2014. http://www.telegraph.co.uk/finance/ personalfinance/insurance/9573224/Dont-lose-money-if-you-lose-yoursmartphone.html.

76. Consumer Reports. Smart phone thefts rose to 3.1 million last year, Consumer Reports finds. 28-5-2014. http://www.consumerreports.org/cro/ news/2014/04/smart-phone-thefts-rose-to-3-1-million-last-year/index.htm.

77. Bracebridge S, Bachmann MO, Ramkhelawon K, Woolnough A. Evaluation of a systematic postal screening and treatment service for genital Chlamydia trachomatis, with remote clinic access via the internet: a cross-sectional study, East of England. Sex Transm Infect. 2012;88:375-81.

78. Public HE. Commissioning, reporting and using chlamydia activity data. 2013. 19-1-2015. http://www.chlamydiascreening.nhs.uk/ps/info-management.asp.

79. Mosholder AD, Mathew J, Alexander JJ, Smith H, Nambiar S. Cardiovascular risks with azithromycin and other antibacterial drugs. N Engl J Med. 2013; 368:1665-8.

80. Ray WA, Murray KT, Hall K, Arbogast PG, Stein CM. Azithromycin and the risk of cardiovascular death. N Engl J Med. 2012;366:1881-90.

81. eMC. Erythromycin 250mg Capsules SPC. 28-10-2014. 20-1-2015. http:// www.medicines.org.uk/emc/medicine/26315/SPC/Erythromycin+250mg + Capsules/\#UNDESIRABLE_EFFECTS.

82. The National Survey of Sexual Attitudes and Lifestyles. Natsal-3. 2014. 17-12015. http://www.natsal.ac.uk/natsal-3.

83. Estcourt C, Sutcliffe L, Cassell J, Mercer CH, Copas A, James L, et al. Can we improve partner notification rates through expedited partner therapy in the UK? Findings from an exploratory trial of Accelerated Partner Therapy (APT). Sex Transm Infect. 2012;88:21-6.

84. Public Health England. Sexually transmitted infections and chlamydia screening in England, 2013. 2014. https://www.gov.uk/government/uploads/ system/uploads/attachment_data/file/345181/Nolume_8_number_24 hpr2414_AA_stis.pdf.

85. Tideman RL, Chen MY, Pitts MK, Ginige S, Slaney M, Fairley CK. A randomised controlled trial comparing computer-assisted with face-to-face sexual history taking in a clinical setting. Sex Transm Infect. 2007;83:52-6.

86. Rogers SM, Willis G, Al-Tayyib A, Villarroel MA, Turner CF, Ganapathi L, et al. Audio computer assisted interviewing to measure HIV risk behaviours in a clinic population. Sex Transm Infect. 2005;81:501-7.

87. Richens J, Copas A, Sadiq ST, Kingori P, McCarthy O, Jones V, et al. A randomised controlled trial of computer-assisted interviewing in sexual health clinics. Sex Transm Infect. 2010;86:310-4.
88. Kurth AE, Martin DP, Golden MR, Weiss NS, Heagerty PJ, Spielberg F, et al. A comparison between audio computer-assisted self-interviews and clinician interviews for obtaining the sexual history. Sex Transm Dis. 2004;31:719-26.

89. Fairley CK, Sze JK, Vodstrcil LA, Chen MY. Computer-assisted self interviewing in sexual health clinics. Sex Transm Dis. 2010;37:665-8.

90. Fernando I, Thompson C. Testing time: testing patient acceptance and ability to self-screen for a No-Talk Testing service. Int J STD AIDS. 2013.

91. Kissinger P, Rice J, Farley T, Trim S, Jewitt K, Margavio V, et al. Application of computer-assisted interviews to sexual behavior research. Am J Epidemiol. 1999;149:950-4.

92. Ghanem KG, Hutton HE, Zenilman JM, Zimba R, Erbelding EJ. Audio computer assisted self interview and face to face interview modes in assessing response bias among STD clinic patients. Sex Transm Infect. 2005:81:421-5.

93. Horner P, Boag F, the Clinical Effectiveness Group. 2006 UK National Guideline for the Management of Genital Tract Infection with Chlamydia trachomatis. 2006

94. Macleod J, Salisbury C, Low N, McCarthy A, Sterne JA, Holloway A, et al. Coverage and uptake of systematic postal screening for genital Chlamydia trachomatis and prevalence of infection in the United Kingdom general population: cross sectional study. BMJ. 2005;330:940.

95. Ferreira A, Young T, Mathews C, Zunza M, Low N. Strategies for partner notification for sexually transmitted infections, including HIV. Cochrane Database Syst Rev. 2013;10:CD002843.

96. Low N, Welch J, Radcliffe K. Developing national outcome standards for the management of gonorrhoea and genital chlamydia in genitourinary medicine clinics. Sex Transm Infect. 2004;80:223-9.

97. Sutcliffe L, Brook MG, Chapman JL, Cassell JM, Estcourt CS. Is accelerated partner therapy a feasible and acceptable strategy for rapid partner notification in the UK?: a qualitative study of genitourinary medicine clinic attenders. Int J STD AIDS. 2009:20:603-6.

98. Trelle S, Shang A, Nartey L, Cassell JA, Low N. Improved effectiveness of partner notification for patients with sexually transmitted infections: systematic review. BMJ. 2007;334:354.

99. General Medical Council. Good practice in prescribing and managing medicines and devices. 2013. http://www.gmc-uk.org/guidance/ethical_guidance/14316.asp.

100. Althaus CL, Turner KM, Mercer CH, Auguste P, Roberts TE, Bell G, et al. Effectiveness and cost-effectiveness of traditional and new partner notification technologies for curable sexually transmitted infections: observational study, systematic reviews and mathematical modelling. Health Technol Assess. 2014; 18:1-viii.

101. Nicholas A, Bailey JV, Stevenson F, Murray E. The Sexunzipped trial: young people's views of participating in an online randomized controlled trial. J Med Internet Res. 2013;15:e276.

102. Allison S, Bauermeister JA, Bull S, Lightfoot M, Mustanski B, Shegog R, et al. The intersection of youth, technology, and new media with sexual health: moving the research agenda forward. J Adolesc Health. 2012;51:207-12.

103. Bailey JV, Murray E, Rait G, Mercer CH, Morris RW, Peacock R, et al. Interactive computer-based interventions for sexual health promotion. Cochrane Database Syst Rev. 2010;9:CD006483.

104. Jones K, Eathington P, Baldwin K, Sipsma H. The impact of health education transmitted via social media or text messaging on adolescent and young adult risky sexual behavior: a systematic review of the literature. Sex Transm Dis. 2014:41:413-9.

105. Bull SS, Levine DK, Black SR, Schmiege SJ, Santelli J. Social media-delivered sexual health intervention: a cluster randomized controlled trial. Am J Prev Med. 2012;43:467-74.

106. McClean H, Chair BASHH National Audit Group, Radcliffe K, Sullivan A, AhmedJushuf I. BASHH Statement on Partner Notification for Sexually Transmissible Infections. 3-7-2012. 28-8-2013. www.bashh.org/documents/4445.pdf.

107. Society of Sexual Health Advisers. The Manual for Sexual Health Advisers. 2004. http://www.ssha.info/wp-content/uploads/ha_manual_2004_ complete.pdf.

108. National Chlamydia Screening Programme. Patient Group Direction for the administration of azithromycin for Chlamydia trachomatis. 2012. 20-4-2015. http/// www.medicinesresources.nhs.uk/en/Communities/NHS/PGDs/PGD-DevelopmentImplementation/National-templates/Azithromycin-National-Chlamydia-ScreeningProgramme-Template/.

109. General Medical Council. Consent guidance. http://www.gmc-uk.org/ guidance/ethical_guidance/consent_guidance_contents.asp.

110. Beatty PC, Willis GB. Research synthesis: the practice of cognitive interviewing. Public Opinion Quarterly. 2007;71:287-311. 
111. Estcourt CS, Gibbs J, Sutcliffe L, Gkatzidou V, Tickle L, Hone K, et al. Is an automated online clinical care pathway for people with genital chlamydia (chlamydia-OCCP) within an eSexual health clinic feasible and acceptable? Proof of concept study. Sex Transm Infect. 2015;91:A55.

112. NHS Research Health Authority. Does my project require review by a Research Ethics Committee? 2013. http://www.hra.nhs.uk/documents/2013/09/does-myproject-require-rec-review.pdf.

Submit your next manuscript to BioMed Central and we will help you at every step:

- We accept pre-submission inquiries

- Our selector tool helps you to find the most relevant journal

- We provide round the clock customer support

- Convenient online submission

- Thorough peer review

- Inclusion in PubMed and all major indexing services

- Maximum visibility for your research

Submit your manuscript at www.biomedcentral.com/submit 